\title{
El hibridismo cultural en Ios inicios del Ballet Nacional Chileno ${ }^{51}$
}

\author{
doi: 10.33264/rpa.202001-11 \\ Paula Tapia Silva \\ Escuela de Danza y Coreografía \\ Facultad de Artes de la Comunicación UNIACC
}

\section{Resumen}

La investigación aborda el análisis de las características de hibridación cultural en los inicios del Ballet Nacional Chileno, creado en 1941, bajo las premisas estéticas de la danza moderna expresionista alemana. Se revisan los referentes teóricos más importantes de la interculturalidad y el hibridismo latinoamericano para posteriormente examinar la realidad sociopolítica y la producción artística desde los años cuarenta hasta inicios de los setenta. Finalmente se explica la aceptación del modelo de danza alemana en el contexto intelectual y artístico chileno y su posterior evolución hacia un producto coreográfico con sello identitario propio.

Palabras clave: Ballet Nacional Chileno, danza expresionista alemana, hibridismo cultural.

\section{Abstract}

This article analyzes the salient features of cultural hybridism during the beginnings of the National Chilean Ballet, created in 1941, using the aesthetic premises of German modern expressionism dance. It uses the theoretical frameworks of interculturalism and Latin American hybridism, linking the aesthetical analysis with the sociopolitical context and the art production in the period starting in the forties until the early 70 's. The paper explains the acceptance of the modern German dance in the intellectual and artistic Chilean contexts of that period and the evolution of Chilean dance towards a choreographic production which developed an identity with particular local features.

Keywords: Chilean National Ballet, modern expressionist dance, cultural hybridism.

${ }^{51}$ La presente investigación fue realizada con los fondos obtenidos en el CONCURSO ANUAL DE FOMENTO DE LA INVESTIGACIÓN Y MEJORAMIENTO DE LA DOCENCIA UNIACC- 2016. 
Toda cultura es el resultado de una mezcolanza

(Claude Lévy-Strauss)

\section{Introducción}

El ensayo que se presenta a continuación es el primero de una serie de trabajos sobre la historia de la danza nacional cuya motivación es analizar, desde el enfoque de la antropología cultural, el impacto de los procesos de hibridación en la danza chilena. La idea central del trabajo propone que, a pesar de que la danza profesional en Chile inicia de la mano de modelos extranjeros, los artistas nacionales resignifican estos modelos dotándolos de un sentido distintivo, generando un producto que construye de manera creativa sistemas simbólicos que articulan elementos foráneos y locales. La aproximación metodológica que guía este artículo tomará como referente estudios de la antropología cultural que explican los procesos de encuentro entre culturas con foco en la interculturalidad y el hibridismo. También se incorpora la mirada de la sociología del arte, que entiende a la obra como un sistema autorreferente y cerrado que dota al arte de una gran libertad a nivel simbólico y creativo. Bajo este marco conceptual se interpretará en trabajo del Ballet Nacional Chileno/BANCH, entre los años 40 y 70, partiendo de la base que el desarrollo del arte de la danza en Chile está marcado por el referente extranjero de la cultura dominante europea.

La primera escuela profesional nace de la mano de la Universidad de Chile bajo las premisas estéticas vanguardistas del expresionismo alemán el año 1941, casi 20 años después se crea el Ballet de Arte Moderno que responde al estilo neo-clásico desarrollado principalmente en Francia. Ambas corrientes van a verse influenciadas por la cultura local y los movimientos identitarios surgidos en la década de los 60 , promoviendo que la nueva generación de coreógrafos/as incorporen la forma de moverse, música y temática regional a sus obras. Debido al golpe militar de 1973, el desarrollo de la danza se va a ver interrumpido. El exilio de varios creadores, la censura a nivel temático y el corte del financiamiento estatal para diversas iniciativas que promovían el desarrollo de la danza a nivel comunitario, van a jibarizar considerablemente la producción danzaria. Posteriormente, en la década de los 80 comienza una reactivación de las artes en general, haciendo eco de los movimientos de renovación impulsados por el arte pop, el abstraccionismo y el formalismo. En el caso de la danza, van a jugar roles muy importantes los centros culturales, francés, norteamericano y alemán, que promueven el intercambio con artistas internacionales de primer nivel, permitiendo el acercamiento de las y los creadores chilenos a la danza teatro europea y la danza postmoderna norteamericana. Por otro lado, surge la danza como espectáculo televisado, lo que va a permitir un consumo masivo de montajes que replican la estética de la comedia musical de moda en Broadway. 
Como punto de partida de esta serie de artículos, a continuación se revisará el fenómeno del hibridismo cultural como producto de la instalación de la estética europea del expresionismo alemán en el Ballet Nacional Chileno. En primer lugar se presentará el marco teórico que guía este análisis, posteriormente se hará una revisión histórica del surgimiento de la danza moderna profesional y, finalmente se presentarán los alcances y conclusiones del estudio.

\section{La interculturalidad y el hibridismo en los sistemas simbólicos del arte}

Para entender la cultura y los productos que de ella se desprenden, como la danza, es fundamental comprender los procesos actuales de intercambio e hibridación, así como también, la noción de la obra de arte como un sistema simbólico autorreferente y cerrado.

Cuando Néstor García Canclini (2009) dice que todas las culturas actuales son culturas de frontera, hace referencia a que los grupos sociales no son homogéneos sino una compleja mixtura entre los saberes propios y los de nuestros vecinos. Somos producto del intercambio de culturas, ninguna sociedad es absolutamente "pura" o se mantiene totalmente asilada. Por ejemplo, los pueblos Mesoamericanos del posclásico tardío, intercambiaban productos y conocimientos en los mercados que se instalaban periódicamente a lo largo del territorio (Carrasco \& Broda 1978); Chapman, 1959), este canje de bienes incluía, indiscutiblemente, el intercambio simbólico, religioso y de significado que acompañaba al objeto tranzado (Attolini y Brambila, 2008). El espacio donde se producía la transacción ha sido denominado por Néstor García Canclini (2009) como una zona fronteriza, en la que, de manera similar a nuestras grandes metrópolis, fluía el intercambio gracias a la diversidad cultural que se encuentra en las ciudades debido a la migración.

Toda cultura se ve influenciada, en mayor o menor medida, por el contacto con otras culturas. Pero los procesos de adaptación que se generan como resultado de ese encuentro pueden tener connotaciones positivas o negativas producto de las estrategias desplegadas por las comunidades para incorporar o rechazar las influencias foráneas. El historiador Peter Burke (2010) propone que las reacciones se han presentado, generalmente, dentro de cuatro escenarios: la Moda de lo Extranjero, la Resistencia, la Purificación Cultural y la Segregación cultural. Pero enfatiza que en la actualidad, ante el fenómeno de la globalización, deberíamos tender cada vez más hacia la Disglosia Cultural, que nos plantea la posibilidad de ser biculturales en un contexto de cultura global. O sea, participar de la globalización manteniendo las características diferenciadoras locales. Esto implica la oportunidad de generar nuevas formas de entender el mundo y establecer relaciones mucho más flexibles frente a los entornos diversos. Si bien este encuentro no siempre es beneficioso para ambas 
partes, más bien, generalmente, conlleva una relación inequitativa marcada por la situación de desigualdad entre la cultura dominante y la dominada, hoy en día podemos empezar a apreciar reacciones interculturales en las que la diferencia cultural es valorada y comprendida como parte esencial de nuestras sociedades. Incluso, esta situación se promueve desde las políticas públicas al plantear la riqueza de los proyectos educativos interculturales (Treviño et al, 2012).

La interculturalidad es una aspiración que se presenta como un nuevo escenario en el que el encuentro de dos sistemas simbólicos diferentes involucra una transformación para ambos grupos. Para referirse al proceso de apropiación del conocimiento intercultural, Néstor García Canclini acuña el término de Hibridismo.

No se trata de una palabra nueva, explica, de hecho tiene un amplio uso en la biología. En el caso de las ciencias sociales, podemos remontarnos hasta la época de la antigüedad greco romana, "Plinio el Viejo mencionó la palabra al referirse a los migrantes que llegaron a Roma en su época”, también el término describe procesos "interétnicos y de descolonización, viaje y cruces de fronteras, el encuentro entre Europa y América durante la conquista y fusiones artísticas, literarias y comunicacionales" (García, 2009, p. I-II).

De acuerdo a la mirada de García Canclini la hibridación "no es sinónimo de fusión sin contradicción" (2009, p.II), sino que también da cuenta del conflicto generado actualmente en una América Latina, con altos índices de desigualdad, migraciones intercontinentales y globalización de la información. Específicamente define hibridismo como "procesos socioculturales en los que estructuras o prácticas discretas, que existían en forma separada, se combinan para generar nuevas estructuras, objetos y prácticas" (García, 2009, p.III). El término contribuye a “identificar y explicar múltiples alianzas fecundas: por ejemplo, el imaginario precolombino con el novohispano de los colonizadores y luego con el de las industrias culturales [...], la estética popular con la de los turistas [...], las culturas étnicas nacionales con las de las metrópolis [...], y con las de las instituciones globales" (2009, p.V).

Canclini explica que las prácticas culturales discretas se ven hibridadas por procesos migratorios, turísticos y de intercambio económico o comunicacional, pero también presta gran atención a la creatividad individual y colectiva para generar estas nuevas estructuras sígnicas y simbólicas. Lo que busca el hibridismo es "reconvertir un patrimonio" y que un conjunto de saberes se reinserte en un nuevo contexto (2009, p. V-VI).

Si bien los estudios de García Canclini se focalizan en el análisis sociopolítico de los pueblos latinoamericanos, la importancia que da a la creatividad para entender las respuestas individuales y grupales para resignificar el encuentro de culturas, le 
permiten aplicar el término a la creación artística. También los teóricos del arte Gaspar Galaz y Milan Ivelic (1988), definen gran parte del arte chileno como híbrido. Bajo el prisma del sociólogo Niklas Luhmann (2005), el arte ofrece la oportunidad de que algo "diferente" se pueda designar como realidad y favorece la mirada desde el otro lado, haciendo patente cosas que muchas veces no queremos ver. Para comprender la oportunidad que presenta la creación es necesario aclarar que el arte es un sistema autónomo, o sea sus reglas de funcionamiento y significado se establecen en función de sí mismo. Por este motivo la obra crea una realidad que solo es aceptable dentro del contexto artístico que le da sentido (Luhmann, 2005). En otras palabras, en la sociedad moderna, en la que las funciones se han complejizado, vamos a encontrar altos niveles de especialización que nos llevan a desarrollar sistemas de producción específicos. Y cada sistema responde a lógicas que le son propias en relación a su particular existencia y correcto funcionamiento. Por ejemplo, las lógicas del mercado no son las mismas que las lógicas del arte. Es por ello que la noción de belleza responde a un patrón desarrollado dentro del sistema simbólico del arte y, en muchas ocasiones, no es comprendido por la gran mayoría de la gente pues no manejan las claves de interpretación del sistema. Obviamente existen vasos comunicantes y los sistemas se nutren recíprocamente, pero la interpretación que se hace del entorno es única y autorreferente ${ }^{52}$.

El arte actual permite libertades para crear realidades más grandes que las de la religión y el lenguaje (que también son sistemas de designación simbólica) ya que la capacidad de combinación de los elementos sígnicos y simbólicos del arte es prácticamente ilimitada. Cada obra es comprensible dentro de un sistema cerrado, pero también cada nueva creación puede hacer uso de signos de otros sistemas simbólicos (Luhmann, 2005). Es un producto totalmente híbrido, en el que se visibilizan los procesos de elaboración, reflexión y creación de significados. Además es un campo inestable y conflictivo, que proyecta, por lo general de manera anticipada al resto de las esferas de la sociedad, las oportunidades de la hibridación (García, 2009).

En el arte de la época globalizada no solo encontramos fusión y mezcla, sino también confrontación y diálogo. Lo que hace posible que en un contexto que tendía hacia la universalización, se comiencen a reconocer y valorar las diferencias de grupos minoritarios, permitiendo el diálogo de la interculturalidad (García, 2009)

En síntesis, el estudio de los procesos culturales permite entender cómo se producen las hibridaciones y comprender la heterogeneidad en la que vivimos. En este contexto, el arte es un sistema cerrado de gran complejidad que tiene mucha libertad para incorporar, reformular y fusionar elementos de otras culturas. El caso de la 
danza chilena presenta varios fenómenos muy interesantes para acercarnos al estudio de la apropiación y producción cultural. A continuación se revisará la creación del Ballet Nacional Chileno-BANCH, cuyo estilo de inicio no tuvo ninguna relación con el baile nacional, sino que replicó la danza moderna expresionista de la mano de los grandes maestros Ernst Uthoff, Lola Botka y Rudolf Pescht.

\section{Modelos extranjeros en la danza chilena}

La danza en Chile nace de la mano de modelos estéticos extranjeros. La primera escuela profesional de esta disciplina -fundada en la Universidad de Chile en 1941estuvo a cargo del coreógrafo y bailarín alemán Ernst Uthoff quien en conjunto con Lola Botka y Rudolf Pescht, instalaron en nuestro país los principios de la danza moderna expresionista alemana (Cifuentes, 2007; Montecinos, 2002). Pese a la lejanía que tenemos con el país germano, esta situación no es extraña ni ajena a la realidad que vivían la mayoría de los países latinoamericanos, cuyo referente artístico intelectual era principalmente europeo, motivo por el cual los jóvenes artistas e intelectuales basaban su formación y producción en lo que las vanguardias artísticas y, también las escuelas clásicas del viejo continente les ofrecían ${ }^{53}$ (Ivelic, Sommer, Valdés, \& Galaz, 2006).

Aproximadamente dieciséis años antes, en 1925, nuestros vecinos argentinos habían fundado el Ballet del Teatro Colón, adscribiendo a los ideales estéticos del ballet neoclásico ${ }^{54}$ (teatrocolon.org). Pasaron varios años antes de que Chile tuviera su propio cuerpo estable de danza, pero lo más llamativo, es que el ballet chileno no siguió el modelo estético de la danza clásica, que con una tradición de más de 200 años era considerada la base de la formación de todo intérprete, sino que se optó por una propuesta sumamente vanguardista para su época. El Ballet Nacional ChilenoBANCH se fundó sobre la base de los lineamientos técnicos y estilísticos de la danza expresionista alemana. En todo caso si nos situamos en la primera mitad del siglo XX en América Latina, ni el ballet clásico ni la danza moderna tenían ninguna relación con el folklore local ni las formas de moverse de los latinoamericanos. Entonces cabe preguntarse ¿por qué se importa un modelo extranjero para crear la danza nacional? Para responder esta pregunta es necesario revisar los antecedentes históricos y sociopolíticos que rodearon el surgimiento de este arte en nuestro país. Efectivamente la sociedad chilena bailaba, mas no con una noción de espectáculo, sino para entretenerse $y$, si bien no hay serios registros al respecto, al parecer replicaban los bailes de moda europeos y algunas "danzas del pueblo" (Cifuentes,

\footnotetext{
53 El referente europeo en la plástica nacional y el posterior sello nacional está ampliamente desarrollado en el libro Pintura en Chile 1950-2005 de los autores Ivelic, Sommer, Valdés, y Galaz.

54 El primer director de la compañía fue Adolf Bolm, quien se había formado en el más estricto estilo clásico del Ballet Mariinski (ex Kírov) de San Petersburgo y posteriormente integró los Ballets Russes de Diaghilev (teatrocolon.org.ar).
} 
2008; Brenner, s.f.). Seguramente en los encuentros sociales debe haber sido posible captar el hibridismo de las danzas, pero no hay estudios que den cuenta del fenómeno 55 .

Con respecto a la danza escénica el modelo estético era el europeo, registros de la prensa de época mencionan las giras de algunas figuras importantes del ballet (incluso Anna Pavlova estuvo en Chile en dos ocasiones durante la primera guerra mundial) (Cifuentes, 2008, Ehrman, 2009) que ayudaron a ir formando audiencias y definieron los parámetros de la danza aceptada por la elite económica e intelectual. También estas visitas permitieron que algunas maestras y maestros se quedaran en Chile dirigiendo pequeñas academias destinadas principalmente a la formación de las niñas de la alta sociedad (Montecinos, 2002). Aunque hubo varios intentos por iniciar un cuerpo estable que nutriera, principalmente, de bailarines/as a la Opera, la iniciativa no se concretó y el ballet clásico perdió el terreno ganado (Cifuentes, 2008).

\section{El BANCH: un producto importado de Alemania}

Posiblemente son varios los motivos que ayudaron a que los inicios profesionales de la danza en nuestro país fueran modernos. En primer lugar, ya se enseñaba en academias privadas los lineamientos de la danza moderna basada en el modelo expresionista de Dalcroze-Laban-Wigman ${ }^{56}$. Las vanguardias artísticas europeas eran un referente obligado para los artistas nacionales, de hecho músicos, pintores y escritores no consideraban completa su formación si esta no incluía un viaje a Europa.

Al parecer este fenómeno no era distintivo de nuestro país, García Canclini (2009) menciona que

La primera fase del modernismo latinoamericano fue promovida por artistas y escritores que regresaban a sus países luego de una temporada en Europa. No fue tanto la influencia directa, trasplantada, de las vanguardias europeas lo que suscitó la veta modernizadora en la plástica del continente, sino las preguntas de los propios latinoamericanos acerca de cómo volver compatibles su experiencia internacional con las tareas

\footnotetext{
55 Solo después de los años 40 se comienza a recopilar las manifestaciones folklóricas nacionales con la creación del Departamento de Investigaciones Folklóricas de la Facultad de Arte de la Universidad de Chile (Mellafe, Rebolledo \& Cárdenas, 1992, 194-197).

56 La danza expresionista alemana surge a principios del siglo XX como una propuesta rupturista que pretende alejarse de los principios impuestos por el ballet clásico. Quienes adherían a esta corriente buscaban dar cabida a la expresión de sentimientos y emociones a través del movimiento, por ello rechazaban la rigidez de las posturas impuestas por la técnica clásica y exploraban en las capacidades expresivas del cuerpo. Sus precursores son el músico Emile Dalcroze (Suiza 1865- 1950 ), el creador de la notación para la danza Rudolf Laban (Hungría 18791958 ) y la coreógrafa Mary Wigman (Alemania 1886-1973), posteriormente se les sumarán el pedagogo Sigurd Leeder (Alemania 1902-1981) y el coreógrafo Kurt Jooss (Alemania 1901-1979).
} 
que les presentaban sociedades en desarrollo (pág. 75).

El artista plástico Ignacio del Pedregal fue uno de los chilenos que viajó a Alemania seducido por la pintura expresionista, una vez allá conoció a Mary Wigman, quien es considerada pionera (en conjunto con Rudolf Laban) en la creación del expresionismo en danza. Fascinado por el movimiento expresivo, al regresar a su tierra natal, Pedregal guardó los pinceles y se dedicó a bailar y enseñar danza en el subterráneo del Museo Nacional de Bellas Artes. Sus clases eran muy diferentes a la técnica clásica impartida en las pocas academias de la época, ya que primaba el movimiento libre, pero también eran mixtas lo que marcaba una enorme diferencia (Cifuentes 2008). Además del trabajo del entusiasta pintor-bailarín, es importante mencionar a dos extranjeras que fomentaron el gusto de la sociedad santiaguina por la danza moderna, se trata de Andree Haas, discípula de Emile Jaques Dalcroze ${ }^{57}$ y Elsa Martin, quien también había estudiado con la coreógrafa Wigman (Montecinos, 2002). Por un lado Pedregal dotó a la danza de un marco teórico vanguardista y Haas $^{58}$ y Martin la acercaron a los espacios universitarios.

En segundo lugar, la élite intelectual y política era bastante progresista. Como ya se mencionó, los artistas estaban muy comprometidos con los movimientos de vanguardia que promovían la ruptura con la estructura clásica y fomentaban la creación nacional. Durante el período del rector Juvenal Hernández (1933-1953) se creó, entre otras, la Facultad de Artes de la Universidad de Chile, facilitando así el camino para impulsar una serie de acciones que cimentaron las bases para el desarrollo sistemático del arte y la cultura. En la Facultad confluyeron el Conservatorio de Música, la Academia de Bellas Artes, la Escuela de Artes Decorativa y el Museo Nacional de Bellas, estableciendo como una de las premisas fundamentales la promoción de la creación nacional (Mellafe, Rebolledo \& Cárdenas, 1992). En este contexto había una actitud muy proclive a aceptar una postura modernista en el arte. Cabe destacar que las campañas de fortalecimiento de la educación del presidente Pedro Aguirre Cerda (1939-1941), orientadas hacia la clase media, permitieron ampliar la población educada. En síntesis, las políticas públicas, estaban claramente dirigidas a robustecer la educación laica que favorecía el desarrollo profesional de las artes propiciando el avance de las corrientes de vanguardia.

El tercer motivo que impulsó la estética expresionista en la danza de nuestro país es la visita a Chile, en 1940, de una de las compañías más destacadas de su época, el Ballet Jooss. La compañía presentaba su obra más importante "la Mesa Verde"

\footnotetext{
57 Creador del método de enseñanza musical Dalcroze que experimenta la música a través de la utilización del movimiento corporal.

58 Andree Haas ejercía docencia en el Instituto de Educación Física y en el Conservatorio Nacional de Música. 
reconocida a nivel internacional y premiada en el Congreso Internacional de Danza en La ciudad de París el año 1932. La obra mostraba la inutilidad de las negociaciones de los políticos (en torno a una mesa verde) al ser incapaces de detener el estallido de la guerra, adentrándose con cada acto en el dolor y la muerte que acompaña los conflictos bélicos. La coreografía de Kurt Jooss era sin duda bastante lúcida y premonitoria, pero además su lenguaje de movimiento se basaba en la expresión, el flujo, el contraste de energía y las combinaciones rítmicas que apoyaban el desarrollo de la idea que se quería expresar. La obra causó furor entre el público santiaguino y Ernst Uthoff, quien ejercía el cargo de director en ausencia de Jooss, en conjunto con la bailarina Lola Botka y el bailarín Rudolf Pescht, fueron invitados a formar la compañía de la Universidad de Chile. Aunque no aceptaron inmediatamente, pues el Ballet Jooss aun debía continuar su gira por Latinoamérica, al llegar a Venezuela la agrupación se disolvió, debido a que había estallado la II Guerra Mundial y no había más contratos para continuar la gira (Hidalgo, 2002).

Al llegar a Chile se encuentran con una situación de gran precariedad, no había bailarines/as ni estudiantes, ni siquiera había salas de clases. Era necesario partir de cero. Comenta Lola Botka que llamaron a postulación abierta y llegaron un sinnúmero de aspirantes de diferentes clases sociales y con heterogéneas expectativas e intereses. La gran cantidad de candidatos/as "permitió seleccionar a quienes realmente les interesaba la danza y nada más" 59 . Resulta importante destacar que la danza moderna, en el contexto del gobierno de Pedro Aguirre Cerda, resultó atractiva para jóvenes de ambos sexos, independientemente de su extracción socioeconómica. Finalmente, no sin dificultad, este grupo de estudiantes nacionales y sus maestros europeos, llevaron adelante el proyecto de crear una compañía professional. Tras este breve recuento de los sucesos que dieron vida al BANCH, se analizarán los procesos de hibridación que lleva a que un producto importado vaya adquiriendo un sello local.

\section{Danza chilena: expresionista pero con un sello latinoamericano}

Para empezar, no podemos obviar la gran fascinación que sentían los intelectuales chilenos por el arte del viejo continente. Si bien, la mayoría de los historiadores coinciden en que toda cultura se ve influenciada, por el contacto con otras culturas, el fenómeno de la Moda de lo Extranjero que, según Burke, despliegan algunas comunidades para incorporar las influencias foráneas, se vio exacerbado en nuestro país. Se importó el modelo replicando la formación técnica, teórica y coreográfica de la danza expresionista. Tanto la escuela como la compañía contaron con la presencia de los precursores, esto permitió tener la experiencia directa de trabajar con Kurt

59 Conversación personal con Lola Botka en marzo del año 2000.

Revista Pensamiento Académico de la Universidad UNIACC

Vol. $3 \mathrm{~N}^{\circ} 1,2020$ 
Jooss y Sigurd Leeder ${ }^{60}$. Aún hoy en día, las bases teóricas de la danza moderna expresionista se enseñan en algunas escuelas de danza y la historiadora chilena María José Cifuentes (2008) enfatiza que en la danza contemporánea nacional se pueden encontrar los rastros de este estilo, incluso la escuela de Danza y Coreografía de UNIACC, cuyo sello es la danza espectáculo, incorpora en la asignatura de coreografía la enseñanza de algunos conceptos de la coréutica creada por Rudolf Laban.

Uno de los primeros elementos en los que podemos observar la hibridación es en las temáticas de las coreografías. Volviendo a los inicios del BANCH, a pesar que la metodología de enseñanza era Leeder ${ }^{61}$ y el lenguaje de movimiento expresionistas, las temáticas fueron tímidamente incorporando elementos con sello local. En 1943, en la segunda presentación del grupo de estudiantes, las y los bailarines más destacados coreografiaron segmentos de la ópera chilena Sayeda (Montecinos, 2002) del chileno Próspero Bisquertt (Cifuentes, 2008) iniciando lo que va a ser una floreciente colaboración con los músicos nacionales. Durante los siguientes años el cuerpo de baile se fortalece y en 1945 hacen su debut oficial con la versión moderna, del coreógrafo Ernst Uthoff, del Ballet Coppelia (Cifuentes, 2008; Montecinos, 2002). Uthoff gana fama como director y coreógrafo y por más de 20 años se mantiene como el pilar estético fundamental del BANCH. Durante este largo período de tiempo se forman varias generaciones de bailarines que irán dando un sello propio a la danza chilena.

La forma de abordar la temática va nutriendo tanto a los coreógrafos alemanes como a las futuras generaciones de bailarines/as. Es el mismo Kurt Jooss ${ }^{62}$, en una visita a Chile en año 1948, quien expone la importancia de hacer del tema no solo un reflejo de emociones, sino el canal de un mensaje que dé cuenta de las motivaciones del artista. Al respecto Cifuentes menciona que las enseñanzas de Jooss pueden ser consideradas como "uno de los primeros antecedentes que generó dentro de la creación coreográfica nacional, la incorporación de la realidad social y los valores humanos como temas en sus obras" (2008, p. 73). Como producto de la formación expresionista, asociada a las vanguardias que rompen con las estructuras simbólicas de la ilustración y el racionalismo, tendremos en Chile importantes vertientes de danza con un explícito compromiso social, ejemplo de ello fue el Ballet Popular, creado en la década de los 70 por Joan Jara y Alfonso Unanue, abanderizado con la campaña de Salvador Allende (Cifuentes, 2008). Otro ejemplo más actual es el Centro

\footnotetext{
60 Kurt Jooss visitó Chile para montar sus obras y crear Juventud para el BANCH, Sigurd Leeder ejerció el cargo de director y maestro de baile de la escuela en la década de los 60 (Cifuentes, 2007)

61 La metodología Leeder establece las bases de la danza moderna educativa que cimienta su trabajo sobre la articulación de los elementos de tiempo energía y espacio asociados al movimiento.

62 Profesor, bailarín y coreógrafo Alemán, creador de la Mesa Verde. Considerado uno de los pioneros de la Danza Expresionista Alemana.
} 
de Danza Espiral, hoy Escuela de Danza de la Academia de Humanismo Cristiano, proyecto liderado desde el año 1985 por Joan Jara y Patricio Bunster. A su vez, vale la pena hacer notar que los procesos de intercambio cultural son bidireccionales, es por ello que no se puede dejar de mencionar que Kurt Jooss, también, fue impactado por el tesón y esfuerzo de la generación de jóvenes que estaban cristalizando el proyecto pionero de una compañía de danza. Como resultado de su visita del año 1948 hizo una coreografía nueva inspirada en el grupo de bailarinas/es con quienes trabajó: la obra de llamó Juventud (Cifuentes, 2008).

También las tradiciones culturales van permeando las temáticas abordadas por el BANCH. El año 51 el Ballet de la escuela estrenó la primera obra de una coreógrafa chilena, El Umbral del Sueño, de Malucha Solari, contaba con un elenco completo de bailarines/as, músicos y escenógrafos nacionales. Al año siguiente fue el turno de Octavio Cintolesi, también alumno de la escuela, quien monta la obra Redes que está inspirada en sus conversaciones con pescadores de Loncura ${ }^{63}$. Posteriormente el 56 inicia su trabajo coreográfico Patricio Bunster, quién será un ícono de la danza nacional hasta su muerte el año 2006. Poco a poco el imaginario precolombino, la cultura popular, y la identidad étnica van haciendo su aparición en las obras de este grupo de creadores. Reflexionando con respecto a la posibilidad de un ballet con inspiración latinoamericana, Bunster (1961) plantea lo siguiente:

Debemos volcar nuestros ojos y nuestro corazón en esas fuentes, pero nada haremos de valedero si ese interés no es genuino y si no nos adentramos en nuestra América con un impulso realmente inquisitivo, amante y creador. Para mí, el Canto General de Neruda no sólo marcó un vuelco importante en su poética, sino que señaló al artista americano una conducta. Ante la ruina muda e inmóvil de Macchu Picchu, siente el deber de roer la piedra, descubrir al hombre allí enterrado, interrogarlo, amarlo y renacer con él. Esa debe ser nuestra postura ante América. Sólo así nacerá un Ballet Americano.

Aquellos que elijamos esta meta, enfrentamos una tarea ardua y difícil, pues ante todo tendremos que discernir entre los elementos útiles que nos entrega la tradición mundial de la danza y aquellos que signifiquen un lastre para realizar una labor genuinamente creadora. Desde un comienzo tengamos conciencia clara de que necesitamos herramientas nuevas para cavar en este suelo de América. Guardémonos de pensar que se trata solamente de renovar la temática del Ballet, no creamos que para expresar este mundo diferente podremos usar el mismo lenguaje, aplicar

\footnotetext{
63 Pueblo pesquero que forma parte de la zona urbana de la comuna de Quintero en la Región de Valparaíso. Revista Pensamiento Académico de la Universidad UNIACC 
las mismas fórmulas y soluciones que nacieron para otros fines. No caigamos en aquellos engaños y aberraciones estéticas desgraciadamente tan frecuentes en la historia del ballet, que consiste en simular estilos o adoptar tendencias por la mera repetición o imitación de la apariencia de las formas, desconociendo su esencia originaria, su razón expresiva.

[... En resumen, no afrontamos solamente la búsqueda de una temática americana, sino que a ella va aparejada necesariamente la formación de un lenguaje dancístico diferente.

De las consideraciones anteriores emana mi convicción de que el problema del Ballet Americano se liga indisolublemente al problema general del movimiento como medio de expresión del hombre [...] expresándose a través de relaciones de energía, tiempo y espacio. Para mí, eso es coreografía. (Pp.44-47)

Las palabras de Bunster no son el producto de una visión aislada sino que reflejan el sentir de una generación. Los estudios sociales de la historia del arte latinoamericano coinciden en que el surgimiento de la modernización cultural va de la mano de la necesidad imperiosa de los artistas locales de reelaborar las premisas de las vanguardias europeas con el objetivo de contribuir al cambio social (García, 2009). Como resultado de este movimiento, en el período entre los años 60 y 70, la creación coreográfica se diversifica tomando un rol social, llegando a sectores marginados y ocupando espacios comunales, todo esto bajo el alero del Estado. Si bien los y las creadoras formados en la Universidad de Chile, influidas por un fuerte movimiento de renovación política, buscan el elemento identitario nacionalista, no dejan de lado la base teórica del método de Leeder-Laban (coréutica y eukinética).

Observamos que en Chile, hasta el gobierno de Salvador Allende, el producto creativo en danza se nutre de tierras fértiles de diferentes latitudes. Por un lado, se forman en técnicas desarrolladas en Europa, principalmente, Alemania, Francia, Inglaterra y la Unión Soviética (las tendencias de la época eran el moderno con base Leeder-Laban y el ballet neoclásico, que de manera tardía pero imperiosa penetró también en nuestro país a principios de 1960) y, por otro lado, buscaban la inspiración en el nativismo y las raíces latinoamericanas.

\section{Discusión}

Los inicios de la danza profesional chilena están marcados por el referente extranjero de la danza moderna expresionista, cuya base teórica y estilística, va rápidamente interactuando con el contexto sociopolítico y cultural del país. Se trata de un proceso 
de interculturalidad que está teñido por varios factores que articulan la interacción entre la tradición europea y la local.

En primer lugar uno de los hechos distintivos de la forma en que se produce el contacto del arte nacional con la creación internacional, es lo que Peter Burke ha llamado Moda de lo Extranjero. En el Chile de principios del siglo XX el modelo artístico es europeo. Es por ello que la formación de los artistas considera como parte fundamental el viaje a conocer la cuna creativa del viejo continente. Posteriormente, son estos artistas o los visitantes intrépidos que llegan hasta estas lejanas latitudes, quienes forman a las generaciones que repetirán los modelos importados copiando no solo la técnica sino también la estética. Esta situación se ve especialmente reflejada en la Academia de Pintura y el Conservatorio Nacional de Música, ambo inaugurados alrededor de 1850. De la mano de esta tendencia a sobrevalorar el referente de la cultura dominante (en nuestro caso europea), encontramos en Chile una subvaloración de la producción folklórica nacional. Por ejemplo, aproximadamente 100 años después de la creación del Conservatorio se va a comenzar a recopilar la producción tradicional al crearse el Departamento de Investigaciones Folklóricas dependiente de la Facultad de Arte de la Universidad de Chile.

No obstante, pese a una suerte de admiración desmedida por el arte europeo, la importación de los modelos estéticos va a generar procesos de diálogo con lo nacional. En el caso del BANCH, fundado bajo las premisas progresistas del gobierno de Pedro Aguirre Cerda, podemos observar que el diálogo entre el modelo europeo y la temática nacional se produce rápidamente. Quizás solo tarda lo que demora en formarse esa primera generación de bailarines y bailarinas. Si bien Ernst Uthoff siguió siendo la piedra angular del Ballet durante 20 años, podemos apreciar que las nuevas generaciones van gatillando procesos creativos de hibridación que permiten amalgamar temáticas, estructuras, musicales y cualidades de movimiento.

Desde que los jóvenes creadores como Malucha Solari, Patricio Bunster y Octavio Cintolesi comienzan a coreografiar, se aprecia un proceso creativo que permite el diálogo de la estructura sígnica europea con el simbolismo nacional. En una primera etapa se mantiene la estructura formal de la metodología Laban y la temática y ritmos nacionales aportan el elemento local. Por ejemplo, los ritmos de nuestro folklor son interpretados de manera eurítmica con diferentes segmentos del cuerpo aplicando la metodología de Emile Dalcroze. Poco tiempo después comienza una búsqueda consciente de los movimientos que se relacionan con la forma de moverse de campesinos, indígenas, obreros, estudiantes e incluso de la clase alta chilena. El coreógrafo Bunster va a destacar que la danza nace de esa mirada inquisitiva sobre nuestras raíces. 
Otro elemento diferenciador con la historia de la danza de otros países latinoamericanos está dado por el hecho de que el modelo importado va a ser moderno y no clásico. Lo que acentúa mucho la unión entre la creación artística y el contexto social. Levantando la bandera de la conexión política entre arte y sociedad. La danza chilena va a tener un claro discurso político que nace de procesos de hibridación entre la danza expresionista alemana y el contexto chileno. En otras palabras, el modelo que importamos es moderno, por lo que rompe con la jerarquía y las estructuras de movimiento del Ballet, además es expresionista lo que lo conecta estrechamente con la sensación de orfandad y enajenación del ser humano. Estas características facilitan la exploración creativa para dar cuenta de la realidad chilena, y no de la europea. Esta tendencia, que se ver con gran fuerza en el BANCH forma parte de un movimiento social que no solo se genera en Chile, sino que se da en todo el continente. Poco a poco la globalización va aceptando tradiciones diversas promoviendo la creatividad de la cultura tradicional. El ejemplo del discurso de Patricio Bunster muestra un alto nivel de compromiso social, pero también de la búsqueda a nivel corporal.

Por otro lado, en los años 70 se comienzan a avizorar otro tipo de búsquedas de movimiento, asociadas al formalismo, al arte abstracto y al pop, pero ese fenómeno se ve truncado por el golpe militar. En la década de los 80 surgen nuevos referentes estéticos. Es un fenómeno normal de globalización, pero que se ve aumentado por la dictadura militar encabezada por Augusto Pinochet, entre 1973 y 1990. Primeramente, varios intérpretes destacados deben partir al exilio; luego, las temáticas concernientes a lo popular, indigenismo o social, son censuradas o autocensuradas; finalmente muchas de las iniciativas que permitían que la danza llegara a nuevos espacios se quedaron sin financiamiento estatal. Pese a las dificultades que la situación conlleva, o quizás como consecuencia de dichas vicisitudes, las y los artistas de danza van a vivir un momento de gran creatividad e investigación de nuevos lenguajes. Fuera del espacio del $\mathrm{BANCH}$, la danza va a adquirir una característica subversiva y de resistencia de la que incluso muchos artistas no son conscientes. Es en ese momento histórico cuando el arte se manifiesta como un campo inestable y conflictivo que permite visualizar procesos de hibridación sumamente creativos. Es un fenómeno inédito en nuestro país que será profundizado en los siguientes artículos que estarán dedicados a la danza independiente el Chile. 


\section{Referencias}

Attolini, A. \& Brambila, R. (2008). Intercambio y fronteras en el posclásico tardío en Mesoamérica. En Medica, A. (Ed.) Etnografía de los confines: Andanzas de Anne Chapman.

Bunster, P. (1961). Perspectivas de un ballet americano. Revista Musical Chilena (75), pp. 44-47.

Burke, P. (2010). Hibridismo Cultural. Ediciones AKAL.

Carrasco, P. \& Broda, J. (Eds.) (1978). Economía política e ideología en el México prehispánico. Nueva Imagen.

Chapman, A. (1959). Puertos de intercambio en Mesoamérica prehispánica, (Serie Historia, 3), INAH.

Cifuentes, M. (2007). Historia Social de la danza en Chile: visiones, escuelas y discursos 1940-1990. LOM.

Ehrmann, H. (2009). Cuatro décadas de ballet en Chile. Ril Editores.

García Canclini, Néstor (2009). Las culturas híbridas en tiempo de globalización. DEBOLSILLO.

González, H. (productor) y Díaz, R. (director) (2018). Microprogramas en movimiento Carmen Beuchat [Documental]. Tepoz Producciones.

Hidalgo, R. (2002). Lola Botka. Una mujer de ojos inmensos y lúcidos. Revista Impulsos. 6. LOM.

Ivelic, M. \& Galaz, G. (1988). Chile Arte Actual. Ediciones Universitarias de Valparaíso.

Ivelic, M., Sommer, W., Valdes, C., Galaz, G. (2006). Pintura en Chile 1950-2005. Ediciones de la Universidad de Chile.

Lévi-Strauss, C. (1993). Raza y Cultura. Ediciones Cátedra.

Luhmann, N. (2005). El Arte de la Sociedad. Herder. 
Mellafe, R., Rebolledo, A. \& Cárdenas, M. (1992). Historia de la Universidad de Chile. Eds. De la Universidad de Chile.

Montecinos, Y. (2002). Historia del ballet en Chile. Revista Musical Chilena. v.56 Número Especial 2002, pp. 7-27. versión impresa ISSN 0716-2790. http://dx.doi.org/10.4067/S0716-27902002005600002

Pérez, M. (2006). Evolución de la danza profesional clásica y contemporánea en Chile. Consejo Nacional de la Cultura y las Artes.

Ponce, C. (2014). Danza contemporánea independiente y política: movimientos y rupturas en Chile durante las décadas de 1970 y 1980. Cátedra de Artes (N¹5), 102-118.

Reynolds, C. (Spring, 1997). Progressive Ideals and Experimental Higher Education: The Example of John Dewey and Black Mountain College. Education and Culture Vol XIV (Nº pp. 1-9.

https://docs.lib.purdue.edu/cgi/viewcontent.cgi?article=1420\&context=eandc

Teatrocolon.org.ar (s.f.). Ballet Estable. https://teatrocolon.org.ar/es/elteatro/cuerpos-artisticos/ballet-estable

Treviño, E. et Al (2012). Educación para preservar nuestra diversidad cultural: Desafíos de Implementación del Sector de Lengua Indígena en Chile. Ministerio de Educación, República de Chile - Fondo de las Naciones Unidas para la Infancia, UNICEF.

\section{Paula Tapia Silva}

Profesora de Danza/Universidad de Chile, Licenciada en Estética/ Pontificia Universidad Católica de Chile, MLA en Antropología/Universidad de Harvard. Se ha desempeñado como docente de danza y teoría del arte en Chile, México y Estados Unidos. Su trabajo se orienta a la comprensión antropológica del fenómeno del arte. 